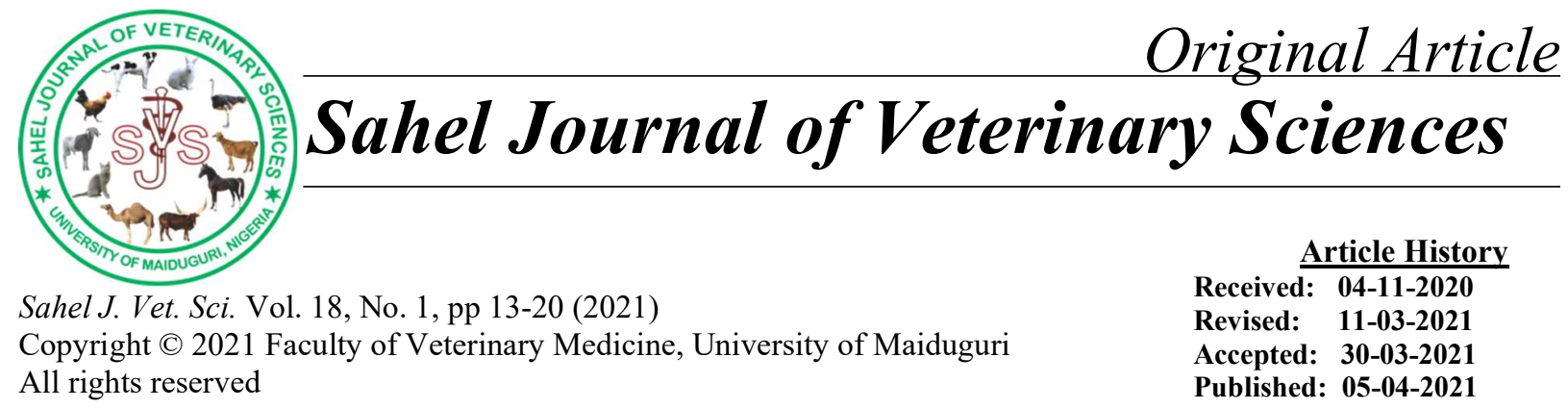

\title{
Effectiveness of Castration with Burdizzo, Calcium Chloride and Olive Oil in Sahel Bucks
}

\begin{abstract}
${ }^{1}$ Laku, D., ${ }^{1}$ Mohammed, A. and ${ }^{2}$ Bukar, M. M.
${ }^{1}$ Department of Surgery and Radiology, Faculty of Veterinary Medicine, University of Maiduguri, P.M.B 1069, Nigeria

${ }^{2}$ Department of Theriogenology, Faculty of Veterinary Medicine, University of Maiduguri, P.M.B 1069, Nigeria

*Author for Correspondence: ddlaku47@gmail.com

ABSTRACT

We evaluated the efficacy of castration with bilateral intratesticular injections of Calcium Chloride Dihydrate $\left(\mathrm{CaCl}_{2}\right)$ in ethanol, Olive Oil as well as Burdizzo technique in twenty Sahel bucks. The bucks were randomly distributed into four groups as A, B, $\mathrm{C}$ and D. Group A served as the control and were given bilateral intratesticular injection of $1.0 \mathrm{ml}$ of normal saline. Bucks in group B were castrated with Burdizzo, while group $\mathrm{C}$ and $\mathrm{D}$ were given bilateral intra testicular injection of $1.0 \mathrm{ml} \mathrm{of} \mathrm{CaCl}_{2}$ and Olive oil, respectively. The sonograms and semen profiles of the bucks were evaluated. The diameters of the testicles and spermatic cords and the semen parameters were measured in real time after castration at days 1, 7, 14, 21, 28 and 60. The diameters in the Burdizzo, $\mathrm{CaCl}_{2}$ and Olive oil castrated bucks significantly increased $(\mathrm{P}<0.05)$ on days 7 and was decreased at day 60. Semen motility was absent in the bucks castrated with $\mathrm{Cacl}_{2}$ after day 14 . The concentration of spermatozoa also decreased significantly on day 7 in all the Burdizzo, $\mathrm{CaCl}_{2}$ and Olive oil castrated goats. Sonogram of testes castrated with $\mathrm{Cacl}_{2}$ showed discreet focal hyperechoic, surrounded by hypoechoic areas within the parenchyma due to the $\mathrm{CaCl}_{2} \mathrm{deposition} \mathrm{The}$ testes of bucks castrated with olive oil were characterized by a central hypoechoic area surrounded by clearly distinguishable hyperechoic areas within the parenchyma. It was concluded that intratesticular injection with Burdizzo, $\mathrm{CaCl}_{2}$ and olive oil resulted in successful castration but $\mathrm{CaCl}_{2}$ injection resulted in earlier azoospermia.
\end{abstract}

Keywords: Burdizzo; Castration; Calcium chloride; Goats; Olive oil; Sahel bucks

\section{INTRODUCTION}

Castration is a procedure to remove testes function by orchiectomy, damaging them irreparably or causing them to atrophy by stricture of the blood supply using physical or chemical methods (Currah et al.; 2009; Al-Asadi and Al-Kadi 2012; Rajkumar 2013). Castration involves the extirpation or suppression of gonadal function (Neto et al., 2014). Following orchiectomy in goats, serum testosterone concentration significantly $(\mathrm{P}<0.01)$ decreased from $6.1 \pm 0.2 \mathrm{ng} / \mathrm{mL}$ on the day of castration to $0.6 \pm 0.0 \mathrm{ng} / \mathrm{mL} 30$ days later (Hasan et al., 2016).

Animals are castrated to make them tractable, to prevent unwanted traits in breeding programs and in some disease conditions such as neoplasms of the testicles or irreversible testicular trauma like chronic orchitis (Stoffel et al., 2009). Generally, castration decrease the frequency of sexual and aggressive behaviour, and it improves the handling in farms.
Surgical castration is expensive and is not usually employed in ruminants except when indicated for pathological conditions (Molony et al., 1995).

Burdizzo castration has been widely used (Stoffel et al., 2009; Sawhney 2016). Although effective, failure of castration has been reported due to improper crushing of the spermatic cord (Stafford et al., 2000). Chemical castration involves the injection of a sclerosing agent into testicular parenchyma to cause irreversible damage (Fordyce et al., 1989; Leoci et al., 2019). Various agents have been used for chemical castration in animals. They include Ferric chloride (Da et al., 1982), Formalin (Ijaz et al. 2000; Bakir et al., 2002; Al-Asadi and Al-Kadi 2012). Chlorhexidine (Mohammed and James 2013), Calcium chloride $\left(\mathrm{Cacl}_{2}\right)$ (Leoci et al., 2014; Leoci et al., 2019). Chemical castration has the advantage of achieving castration objective with a single, inexpensive and permanent technique without the need for any follow-up. It can also be 
used in areas where cutaneous myiasis complicates surgical castrations, or reduce risk of haemorrhage and herniation (Jana and Samanta 2007).

On the other hand, chemical castration has been associated with some complications after intra-testicular injection. These complications include pain, pyrexia and even severe inflammation. However, Al-Asadi and Al-Kadi, (2012) reported that chemical castration with $\mathrm{Cacl} 2$ was more effective than external ligation of the spermatic cord in close castration (elastrator rubber band).

Calcium chloride can be dissolved in water, in alcohol or lidocaine solution (Jana and Samanta 2007). Calcium chloride effectively arrests spermatogensis, androgenesis and libido, with no toxicity and serious side effects (Webe and Barr 1984.). Several investigators have reported that a single, bilateral intra-testicular injection of $\mathrm{Cacl}_{2}$ solution resulted in induction of permanent chemosterilization, including cessation of sperm production and decreased testosterone in male dogs (Jana and Samanta 2007).

Olive oil is a fat obtained from olive seeds (Olea lancifolia). Oleuropein, the active principle of olive oil, is a phenolic compound with antioxidant, anti-inflammatory and antipyretic effect. (Visioliet al., 2002). Olive oil also contains phenoortho-diphenols and various natural antioxidants, tocopherol (Vitamin E), flavones alcohols, sterols, chlorophyll, volatile aromatic substances (De Faveri et al., 2008; Paiva et al., 2011). Post-castration changes in testicular tissue can be monitored by external assessment (calliper measurements), histopathology (biopsies) or imaging (radiography and ultrasonography).

It was suggested that ultrasonography could permit noninvasive evaluation of the internal structure of the scrotum and testes for evaluating physio-pathologic conditions of goat testes or as a routine investigative method during breeding soundness and clinical examination (Sakthivel et al., 2013; Olatunji-Akioye et al., 2018). Furthermore, use of semen analysis in conjunction with sonography is potentially very useful in assessment of fertility status in animals (Gouletsou et al., 2003). For these reasons, ultrasonography was applied in the current study to monitor the changes associated with different castration methods. In addition, it was reported that testes diameter was better accurately depicted with ultrasound compared with measurement of testes diameter with callipers (Andrade et al., 2014).

Ibrahim et al. (2016) stated that of recent, researchers were interested in developing a method for chemical sterilization which may provide a better alternative to surgical castration which would effectively arrest spermatogenesis and androgenesis as well as libido while avoiding toxic or other side effects. Consequently, to find suitable and inexpensive alternative chemical methods of castration for Sahel bucks, this study was designed to determine the morphometric changes as well as echo-textural characteristics of the testes and key semen parameters of spermatozoa concentration and viability associated with Burdizzo, $\mathrm{Cacl}_{2}$ and olive oil castration methods

\section{MATERIALS AND METHODS}

\section{Experimental Animals}

Twenty clinically healthy Sahel bucks aged $1.5-3$ years weighing 15-20 kg body weight were used for the study. The animals were purchased from Maiduguri livestock market in Borno State, Nigeria. The animals were kept at the Large Animal Clinic, Veterinary Teaching Hospital, University of Maiduguri. They were allowed to acclimatize for two weeks before the commencement of the experiment.

\section{Experimental Design}

The bucks were randomly allocated into four groups A, B, C and $\mathrm{D}$ consisting of five animals each. The body weight was recorded and scrotal circumference of each testicle was measured using measurement tape prior to castration and on days $7,14,21$ and 28 after castration.

Bucks in group A served as the control group and were administered intra-testicular injection of sterile water $1 \mathrm{~mL}$ $\left(\right.$ Unisal $^{\circledR}$ ). Group B were castrated using Burdizzo (Supervet ${ }^{\circledR}$, CHIFA, Nowy, Tomysl, Poland). Group C received intra-testicular injection of $1 \mathrm{~mL} 20 \%$ calcium chloride dihydrate (Sigma ${ }^{\circledR}$, London) (Jana et al. 2005). Group D bucks received an intra-testicular injection of $1 \mathrm{~mL}$ Olive oil (Laser Virgin ${ }^{\circledR}$ olive oil Intl. UAE). After each castration method, $3 \mathrm{mLs}$ of blood samples were drawn from the jugular vein into plain vacutainer tubes and serum harvested by centrifugation at $4000 \mathrm{~g}$ for 3 minutes in an electronic centrifuge (Centrifuge $800 \mathrm{~B} \AA$, Union Laboratories, England).

\section{Ethical Statement}

The experiment was conducted in accordance with international guiding principles for biomedical research involving animals (CIOMS, 1985).

\section{Sonography of the Testes}

Ultrasonograhic evaluation of the testes for all the groups A to $\mathrm{D}$ were carried out using an ultrasound scanner (Falco Vet 100® Pic Medical; Holland), connected to a linear array transducer with a frequency of 7.5 MHz (Sony Sao Paulo, Brazil). The bucks were placed on a recumbent position and the entire hair of each scrotal sac was shaved with razor blade. The shaved area was cleaned with $0.2 \%$ Chlorhexidine gluconate (Savlon ${ }^{\circledR}$, Vervaadingdeur, Johnson and Johnson (pty) Ltd, London). Bucks were physically restrained by two assistants and the testes immobilized. The parenchyma echotexture of each testis was scanned in the sagittal, and transverse planes and diameters measured using the built-in callipers (Bukar et al., 2012; Sakthivel et al., 2013; OlatunjiAkioye et al., 2018).

Scanning of the testes and spermatic cords were similarly performed, were on days 7, 14, 21 and 28 post-castration. 
Semen was collected using Bailey ejaculator ${ }^{\circledR}$ (Western Instrument Company, Denver, Colorado) prior to castration and on days 7, 14, 21 and 28. Each buck was restrained by two assistants and the ejaculator probe (lubricated with K-Y Jelly), inserted into the rectum of the buck and used until ejaculation according to manufacturer's instructions. The semen collected were observed and analysed immediately for the volume, progressive motility, livability and concentration. The same procedure was done for subsequent post-castration collections.

Data obtained were analyzed using One Way Analysis of Variance ANOVA. GraphPad Prism ${ }^{\circledR}$ Version 4.0 Software was employed for the data analysis. Analysis was considered as significant at $\mathrm{P}<0.05$.

\section{RESULTS}

The left testicular diameter (Table 1) was not significantly different $(\mathrm{P}<0.05)$ in the control group throughout the 60-day scanning period. However, the diameters in the Burdizzo, $\mathrm{Cacl}_{2}$ and Olive oil castrated groups significantly increased $(\mathrm{P}<0.05)$ from $21.38 \pm 6.90, \quad 19.26 \pm 8.27$ and $25.96 \pm 5.46$ respectively to $27.00 \pm 7.26,22.28 \pm 8.23$ and $29.44 \pm 0.85$ respectively on days 7 and was decreased at day 60 to $23.46 \pm 16.14,23.36 \pm 14.18$ and $24.38 \pm 14.23$, respectively.
Similarly, right testicular diameter (Table 1) was not significantly different $(\mathrm{P}<0.05)$ in the control group during $\mathrm{t}$ he 60 -day scanning period. However, the diameters $(\mathrm{mm})$ in the Burdizzo, $\mathrm{Cacl}_{2}$ and Olive oil castrated groups significantly increased $(\mathrm{P}<0.05) 22.70 \pm 5.90,20.90 \pm 8.81$ and $23.48 \pm 2.66$ respectively to $27.48 \pm 6.47,26.94 \pm 7.71$ and $27.02 \pm 4.49$ respectively on days 7 and was decreased at day 60 to $23.86 \pm 14.40,23.20 \pm 14.23$ and $25.36 \pm 14.26$ respectively (Table 1). The mean spermatic cord diameter of the left before castration with Burdizzo, $\mathrm{Cacl}_{2}$ and Olive oil were 5.62 \pm 2.27 , $6.98 \pm 2.09$ and $5.30 \pm 2.43$ respectively. These values significantly increased $(\mathrm{P}<0.05)$ to $11.74 \pm 5.84,7.06 \pm 2.19$ and $6.02 \pm 2.31$ respectively on day 7 . At day 60 , the mean diameters had decreased to $4.92 \pm 3.05,5.02 \pm 3.04$ and $5.70 \pm 3.44$, respectively (Table 2 ).

The values of right spermatic cord diameter $(\mathrm{mm})$ before castration with Burdizzo, $\mathrm{Cacl}_{2}$ and Olive oil also significantly increased $(\mathrm{P}<0.05)$ from 5.76 $\pm 1.35,5.98 \pm 1.12$ and $6.32 \pm 1.05$ respectively. These values significantly increased $(\mathrm{P}<0.05)$ to $9.86 \pm 3.14,7.90 \pm 1.54$ and $5.78 \pm 1.09$ respectively on day 7 . At day 60 , the mean diameters had decreased to $5.12 \pm 2.87,4.60$ \pm 2.58 and $5.90 \pm 3.51$, respectively (Table 2 ).

Table 1: Diameter of the left and right testicles (mm) in Sahel bucks castrated with Burdizzo, $\mathrm{CaCl}_{2}$ and olive oil

\begin{tabular}{llllllll}
\hline $\begin{array}{l}\text { Castration } \\
\text { Method }\end{array}$ & & \multicolumn{6}{c}{ Testicular diameter $(\mathbf{m m})$ in days after castration } \\
\cline { 3 - 8 } Control & Left & $\mathbf{1}$ & $\mathbf{7}$ & $\mathbf{1 4}$ & $\mathbf{2 1}$ & $\mathbf{2 8}$ & $\mathbf{6 0}$ \\
& Right & $21.98 \pm \pm 7.06$ & $29.02 \pm 3.94^{\mathrm{a}, \mathrm{b}}$ & $26.98 \pm 4.06$ & $26.12 \pm 2.76$ & $27.16 \pm 2.55$ & $21.86 \pm 12.26$ \\
\multirow{3}{*}{ Burdizzo } & Left & $21.38 \pm 6.90$ & $22.28 \pm 8.10$ & $21.98 \pm 9.61$ & $22.74 \pm 9.87$ & $22.46 \pm 8.10^{\mathrm{a}}$ & $18.26 \pm 14.56$ \\
& Right & $22.70 \pm 5.90$ & $27.48 \pm 6.47$ & $27.84 \pm 8.52$ & $28.14 \pm 6.03$ & $28.54 \pm 7.80$ & $23.46 \pm 16.14$ \\
$\mathrm{CaCl}_{2}$ & Left & $19.26 \pm 8.27$ & $19.26 \pm 8.27^{\mathrm{b}, \mathrm{c}}$ & $31.64 \pm 6.34$ & $34.82 \pm 4.34$ & $34.86 \pm 4.83$ & $23.36 \pm 14.18$ \\
& Right & $20.90 \pm 8.81$ & $20.90 \pm 8.81$ & $35.92 \pm 3.16$ & $31.68 \pm 3.14$ & $32.32 \pm 7.56^{\mathrm{b}}$ & $23.20 \pm 14.23$ \\
Olive oil & Left & $25.96 \pm 5.46$ & $29.44 \pm 0.85^{\mathrm{c}}$ & $33.52 \pm 3.89$ & $32.12 \pm 3.21$ & $32.44 \pm 4.56$ & $24.38 \pm 14.23$ \\
& Right & $23.48 \pm 2.66$ & $27.02 \pm 4.49$ & $34.86 \pm 4.80$ & $34.24 \pm 1.40$ & $33.04 \pm 3.62^{\mathrm{c}}$ & $25.36 \pm 14.26$ \\
\hline
\end{tabular}

a,b,c Values with different superscripts within columns differ significantly $(\mathrm{P}<0.05)$

Table 2: Diameter of the left and right spermatic cord $(\mathrm{mm})$ in Sahel bucks castrated with Burdizzo, $\mathrm{CaCl}_{2}$ and olive oil

\begin{tabular}{llllllll}
\hline $\begin{array}{l}\text { Castration } \\
\text { Method }\end{array}$ & & \multicolumn{5}{c}{ Spermatic cords diameter $(\mathbf{m m})$ in days after castration } \\
\cline { 3 - 7 } Control & Left & $6.30 \pm 1.45$ & $8.56 \pm 2.96$ & $6.18 \pm 1.46$ & $5.90 \pm 1.41^{\mathrm{a}, \mathrm{b}}$ & $5.96 \pm 0.58$ & $5.96 \pm 3.80$ \\
& Right & $5.82 \pm 1.99$ & $9.00 \pm 2.34^{\mathrm{a}, \mathrm{b}}$ & $6.06 \pm 1.54^{\mathrm{a}}$ & $6.66 \pm 1.85$ & $4.98 \pm 0.67^{\mathrm{a}}$ & $4.82 \pm 3.18$ \\
\multirow{3}{*}{ Burdizzo } & Left & $5.62 \pm 2.27$ & $11.74 \pm 5.84^{\mathrm{a}, \mathrm{b}}$ & $7.68 \pm 3.05$ & $7.78 \pm 1.61$ & $6.10 \pm 2.04$ & $4.92 \pm 3.05$ \\
& Right & $5.76 \pm 1.35$ & $9.86 \pm 3.14^{\mathrm{b}, \mathrm{c}}$ & $8.04 \pm 2.10$ & $7.26 \pm 1.93$ & $5.58 \pm 1.61$ & $5.12 \pm 2.87$ \\
$\mathrm{CaCl}_{2}$ & Left & $6.98 \pm 2.09$ & $6.98 \pm 2.09$ & $7.12 \pm 2.29$ & $8.98 \pm 1.83^{\mathrm{b}, \mathrm{c}}$ & $6.52 \pm 0.81$ & $5.02 \pm 3.04$ \\
& Right & $5.98 \pm 1.12$ & $5.98 \pm 1.12^{\mathrm{c}}$ & $8.46 \pm 1.81$ & $8.00 \pm 2.21$ & $7.04 \pm 0.77^{\mathrm{b}}$ & $4.60 \pm 2.58$ \\
Olive oil & Left & $5.30 \pm 2.43$ & $6.02 \pm 2.31^{\mathrm{b}, \mathrm{c}}$ & $7.12 \pm 0.94$ & $6.60 \pm 1.27^{\mathrm{c}}$ & $6.22 \pm 0.58$ & $5.70 \pm 3.44$ \\
& Right & $6.32 \pm 1.05$ & $5.78 \pm 1.09^{\mathrm{d}}$ & $8.74 \pm 1.85^{\mathrm{b}}$ & $6.84 \pm 2.53$ & $6.80 \pm 1.06^{\mathrm{c}}$ & $5.90 \pm 3.51$ \\
\hline
\end{tabular}

$\overline{\mathrm{a}, \mathrm{b}, \mathrm{c}, \mathrm{d}}$ Values with different superscripts within columns differ significantly $(\mathrm{P}<0.05)$ 
Semen was no longer ejaculated from the bucks castrated with $\mathrm{CaCl}_{2}$ by day 14 . However, semen was collected from all the other groups (Table 3 ). The colour of semen in bucks castrated with olive oil appeared yellow-straw and different from the other groups.

Semen motility was absent in the bucks castrated with $\mathrm{CaCl}_{2}$ after day 14 whilst motility was observed in the Burdizzo and Olive oil castrated groups until day 28 (Table 4).
The concentration of spermatozoa also decreased significantly on day 7 in all the Burdizzo, $\mathrm{CaCl}_{2}$ and Olive oil castrated goat (Table 5).

By day 60 , all the spermatozoa seen in the semen of $\mathrm{CaCl}_{2}$ and olive oil castrated goats were dead. Only a few live spermatozoa $(2.00 \pm 4.47)$ were seen in the smear of some Burdizzo castrated bucks (Table 6).

Table 3: Semen volume (mL) in Sahel bucks castrated using Burdizzo, $\mathrm{CaCl}_{2}$, and olive oil

\begin{tabular}{lllllll}
\hline Castration & \multicolumn{7}{c}{ Semen collection in days after castration } \\
\cline { 2 - 7 } Method & $\mathbf{1}$ & $\mathbf{7}$ & $\mathbf{1 4}$ & $\mathbf{2 1}$ & $\mathbf{2 8}$ & $\mathbf{6 0}$ \\
\hline Control & $0.64 \pm 0.48$ & $0.72 \pm 0.50$ & $0.62 \pm 0.22^{\mathrm{a}, \mathrm{b}, \mathrm{x}}$ & $0.36 \pm 0.41$ & $0.36 \pm 0.30$ & $0.30 \pm 0.67$ \\
Burdizzo & $0.50 \pm 0.34$ & $1.04 \pm 0.58$ & $0.60 \pm 0.42^{\mathrm{b}, \mathrm{c}, \mathrm{x}}$ & $0.43 \pm 0.40$ & $0.49 \pm 0.62$ & $0.29 \pm 0.62^{\mathrm{a}, \mathrm{x}}$ \\
$\mathrm{CaCl}_{2}$ & $0.50 \pm 0.34$ & $0.48 \pm 0.46$ & $0.00 \pm 0.00^{\mathrm{c}, \mathrm{d}, \mathrm{x}}$ & $0.00 \pm 0.00^{\mathrm{a}, \mathrm{x}}$ & $0.00 \pm 0.00^{\mathrm{a}, \mathrm{x}}$ & $0.00 \pm 0.00^{\mathrm{b}, \mathrm{x}}$ \\
Olive oil & $0.48 \pm 0.29$ & $0.48 \pm 0.46$ & $1.16 \pm 0.47^{\mathrm{d}, \mathrm{x}}$ & $0.86 \pm 0.41^{\mathrm{b}, \mathrm{x}}$ & $1.08 \pm 0.53^{\mathrm{b}}$ & $0.24 \pm 0.53$ \\
\hline
\end{tabular}

a,b,c,d Values with different superscripts within columns differ significantly $(\mathrm{P}<0.05)$

Table 4: Semen progressive motility (\%) in Sahel bucks castrated using Burdizzo, $\mathrm{CaCl}_{2}$, and olive oil

\begin{tabular}{llllllc}
\hline Castration & \multicolumn{7}{c}{ Semen collection in days after castration } \\
\cline { 2 - 7 } Method & $\mathbf{1}$ & $\mathbf{7}$ & $\mathbf{1 4}$ & $\mathbf{2 1}$ & $\mathbf{2 8}$ & $\mathbf{6 0}$ \\
\hline Control & $0.66 \pm 0.20$ & $0.38 \pm 0.36$ & $0.46 \pm 0.27^{\mathrm{a}, \mathrm{b}}$ & $0.38 \pm 0.24$ & $0.20 \pm 0.33$ & $0.46 \pm 0.35$ \\
$\mathrm{Burdizzo}_{\mathrm{CaCl}}$ & $0.46 \pm 0.42$ & $0.12 \pm 0.26$ & $0.37 \pm 0.44$ & $0.34 \pm 0.46$ & $0.34 \pm 0.42$ & $0.00 \pm 0.00$ \\
Olive oil & $0.28 \pm 0.23$ & $0.06 \pm 0.13$ & $0.00 \pm 0.00^{\mathrm{b}, \mathrm{c}}$ & $0.00 \pm 0.00$ & $0.00 \pm 0.00$ & $0.00 \pm 0.00$ \\
& $0.58 \pm 0.34$ & $0.08 \pm 0.17$ & $0.10 \pm 0.12$ & $0.16 \pm 0.23$ & $0.26 \pm 0.32$ & $0.00 \pm 0.00$ \\
\hline
\end{tabular}

a,b,c,d Values with different superscripts within columns differ significantly $(\mathrm{P}<0.05)$

Table 5: Semen concentration $\left(\mathrm{x10}^{9} / \mu \mathrm{l}\right)$ in Sahel bucks castrated using Burdizzo, $\mathrm{CaCl}_{2}$, and olive oil

\begin{tabular}{lllllll}
\hline Castration & \multicolumn{5}{c}{ Semen collection in days after castration } \\
\cline { 2 - 7 } Method & $\mathbf{1}$ & $\mathbf{7}$ & $\mathbf{1 4}$ & $\mathbf{2 1}$ & $\mathbf{2 8}$ & $\mathbf{6 0}$ \\
\hline Control & $48.0 \pm 34.5^{\mathrm{ab}}$ & $23.0 \pm 24.0^{\mathrm{ab}}$ & $15.0 \pm 17.2^{\mathrm{a}}$ & $28.0 \pm 33.3$ & $76.0 \pm 14.5$ & $71.0 \pm 25.5$ \\
Burdizzo & $60.0 \pm 16.4^{\mathrm{bc}}$ & $44.0 \pm 54.0^{\mathrm{bc}}$ & $70.0 \pm 11.0^{\mathrm{b}}$ & $20.0 \pm 44.5^{\mathrm{a}}$ & $17.0 \pm 26.5$ & $0.00 \pm 0.00$ \\
$\mathrm{CaCl}_{2}$ & $94.0 \pm 64.5^{\mathrm{cd}}$ & $28.0 \pm 29.7^{\mathrm{cd}}$ & $0.00 \pm 0.00^{\mathrm{c}}$ & $0.00 \pm 0.00^{\mathrm{b}}$ & $00.0 \pm 00.0$ & $0.00 \pm 0.00$ \\
Olive oil & $41.0 \pm 95.9^{\mathrm{d}}$ & $41.0 \pm 30.5^{\mathrm{d}}$ & $60.0 \pm 10.0$ & $33.0 \pm 34.0^{\mathrm{c}}$ & $17.0 \pm 31.2$ & $0.00 \pm 0.00$ \\
\hline
\end{tabular}

$\overline{\mathrm{a}, \mathrm{b}, \mathrm{c}, \mathrm{d}}$ Values with different superscripts within columns differ significantly $(\mathrm{P}<0.05)$

Table 6: Live total (\%) of spermatozoa in Sahel bucks castrated using Burdizzo, $\mathrm{CaCl}_{2}$, and olive oil

\begin{tabular}{lllllll}
\hline Castration & \multicolumn{5}{c}{ Semen collection in days after castration } \\
\cline { 2 - 7 } Method & $\mathbf{1}$ & $\mathbf{7}$ & $\mathbf{1 4}$ & $\mathbf{2 1}$ & $\mathbf{2 8}$ & $\mathbf{6 0}$ \\
\hline Control & $74.8 \pm 13.9$ & $62.0 \pm 35.6^{\mathrm{ab}}$ & $49.0 \pm 31.5^{\mathrm{a}}$ & $31.6 \pm 36.9$ & $36.0 \pm 39.1$ & $43.00 \pm 6.70$ \\
Burdizzo & $57.0 \pm 38.4$ & $14.0 \pm 19.4^{\mathrm{bc}}$ & $0.00 \pm 0.00^{\mathrm{b}}$ & $26.0 \pm 37.1$ & $18.4 \pm 34.8$ & $2.00 \pm 4.47$ \\
$\mathrm{CaCl}_{2}$ & $55.2 \pm 32.1$ & $5.20 \pm 8.67^{\mathrm{cd}}$ & $0.00 \pm 0.00^{\mathrm{c}}$ & $0.00 \pm 0.00$ & $0.00 \pm 0.00$ & $0.00 \pm 0.00$ \\
Olive oil & $67.8 \pm 38.0$ & $0.00 \pm 0.00^{\mathrm{d}}$ & $1.80 \pm 2.68^{\mathrm{d}}$ & $21.6 \pm 28.7$ & $24.0 \pm 35.6$ & $0.00 \pm 0.00$ \\
\hline
\end{tabular}

$\overline{\mathrm{a}, \mathrm{b}, \mathrm{c}, \mathrm{d}}$ Values with different superscripts within columns differ significantly $(\mathrm{P}<0.05)$

\section{Ultrasonography}

The sonogram of the normal uncastrated testes showed low to moderate echogenicity of the parenchyma with echogenic vaginal tunic (Figure 1). In the Burdizzo castrated bucks (Figure 2), sonogram of testes showed low to moderate echogenicity. The echogenicity increased on days 14 and 21.
Sonogram of testes castrated with $\mathrm{CaCl}_{2}$ (Figure 3) showed discreet focal hyperechoic areas within the parenchyma due to the $\mathrm{CaCl}_{2}$ deposition. The hyperechoic areas were surrounded by hypoechoic areas. These hyperechoic areas were increased in their echogenicity and could be found on days 14, 21 and 28 . 
The sonogram of testes chemically castrated with olive oil (Figure 4). A central hypoechoic area surrounded by clearly distinguishable hyperechoic areas within the parenchyma. These hypoechoic areas persisted until day 28 but were gradually decreased in diameter. At day 60, these hypoechoic areas were not present.

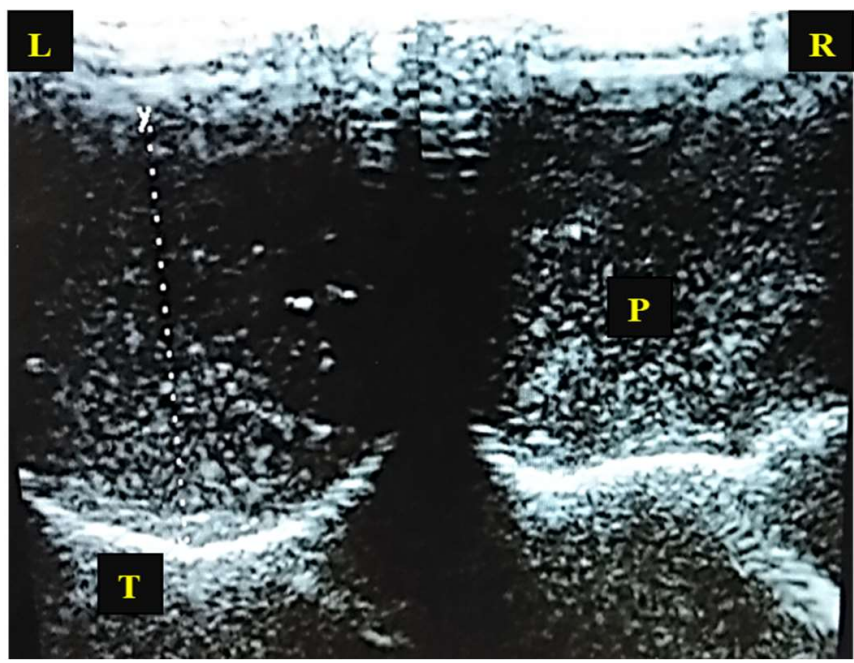

Figure 1: Normal sonographic appearance of Left (L) and right (R) testes in a Sahel buck. Note the hyperechoic Tunica vaginalis (T) (arrows) and moderately echogenic parenchyma (P).

\section{DISCUSSION}

The diameters of the left and right testicles in uncastrated bucks did not change throughout the duration of the current study. There was no significant difference between the left and right testes in the current study as was similarly reported previously (Sakthivel et al., 2013).

However, the diameters in the Burdizzo, $\mathrm{CaCl}_{2}$ and Olive oil castrated groups significantly increased $(\mathrm{P}<0.05)$ from day 7 and was decreased at day 60 to 23 . Swelling of the testes following castration with Burdizzo or chemical methods, which later subsided after a few days have been reported previously (Jana et al., 2005; Al-Asadi and Al-Kadi 2012; Mohammed and James 2013). The resolution of the post castration inflammation and associated swelling indicates healing of damaged tissue and cessation of spermatogenesis provided that the castration was successful. Testosterone production is usually affected as was previously reported that testosterone concentration was significantly decreased from $6.1 \mathrm{ng} / \mathrm{ml}$ on the day of castration to $0.6 \mathrm{ng} / \mathrm{ml} 30$ days later (Al-Asadi and Al-Kadi 2012; Hasan et al. 2016). As was observed for the testes, the diameters of the left and right spermatic cords also increased after castration with Burdizzo, $\mathrm{CaCl}_{2}$ and Olive oil but were decreased by day 28 after castration.

In the current study, compared with semen from uncastrated bucks, the Burdizzo, $\mathrm{CaCl}_{2}$ and Olive oil castrated bucks had reduced volume and quality of semen from on day 7 after castration. In the $\mathrm{CaCl}_{2}$ castrated bucks, semen could not be successfully ejaculated from day 7 after castration. However, semen was successfully collected in the Control, Burdizzo and Olive Oil treated groups although with decreased spermatozoa concentration. This Azoospermia and Aspermia was probably due to the impairment of Sertoli cell and seminiferous tubule function. Similar findings were reported by Al-Asadi and AlKadi (2012) in surgically castrated as well as Formalin (Chemically) castrated bucks.

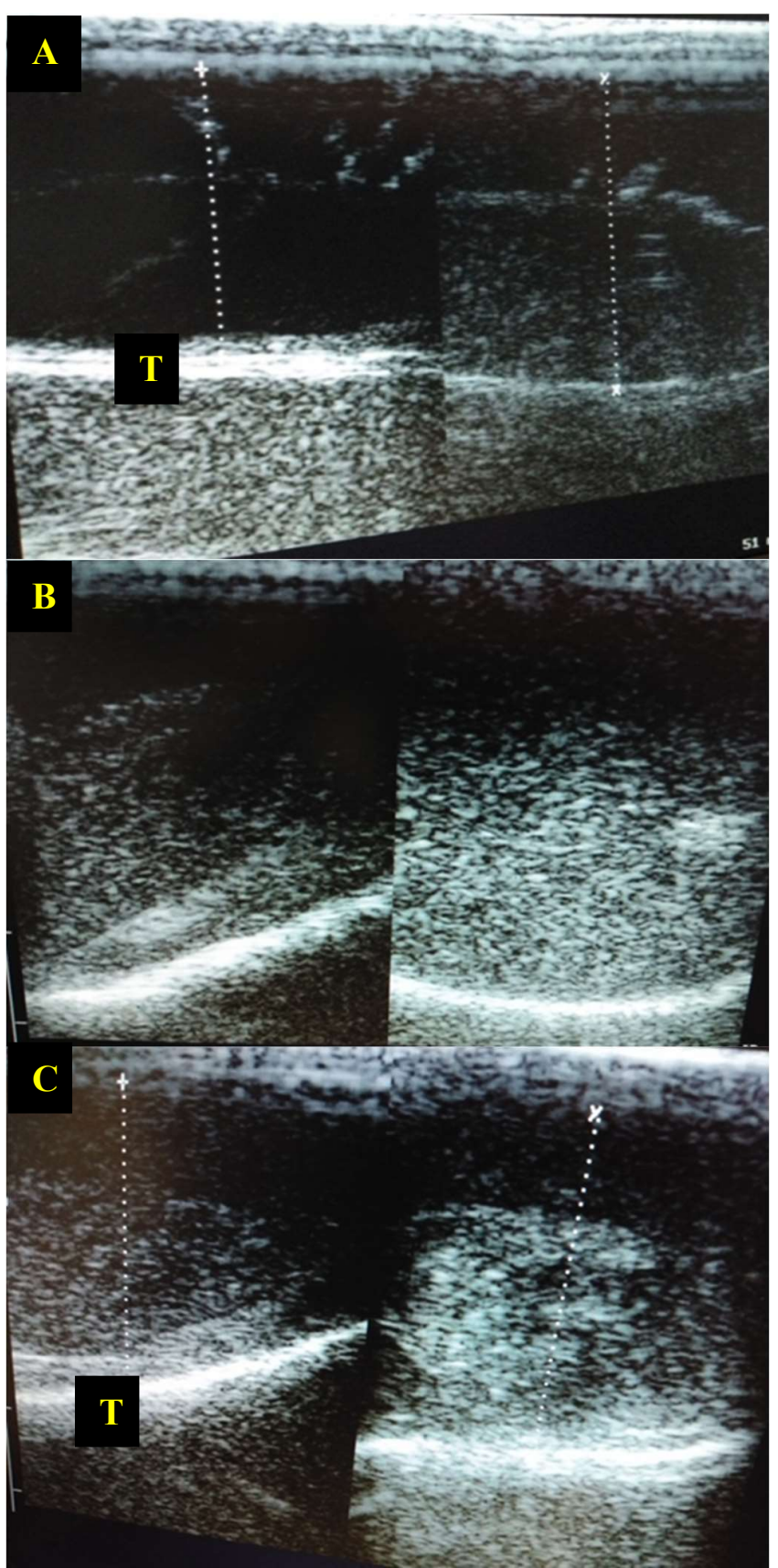

Figure 2: Sonogram of testes castrated with Burdizzo on day 7 (A) showing hypoechoic parenchyma and Tunica vaginalis $(\mathrm{T})$. By day 14 , the testes showed moderate echogenicity (B). The sonographic appearance of the testes by day 21 showed increased echogenicity within the parenchyma. 

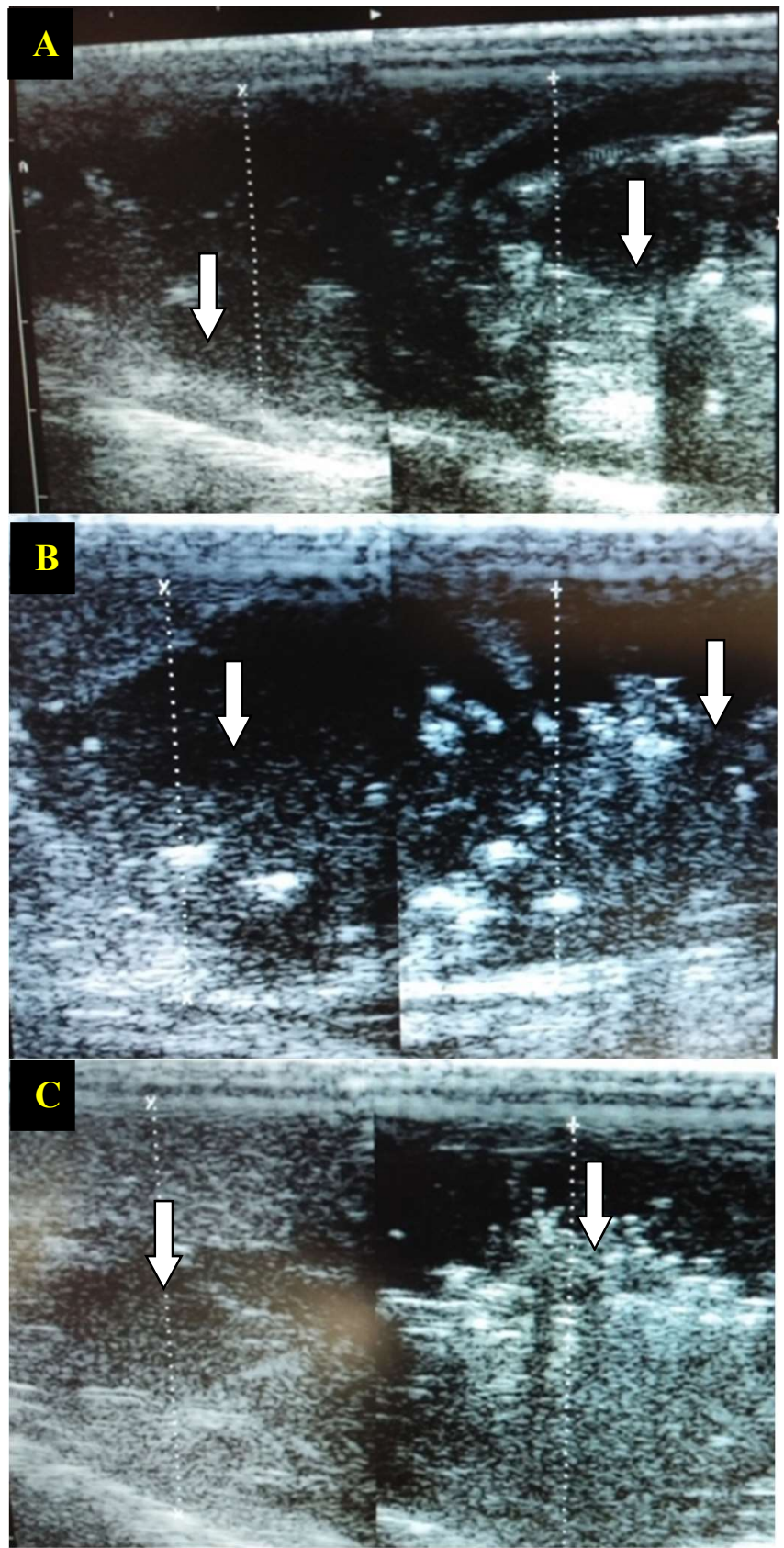

Figure 3: Sonogram of testes castrated with $\mathrm{CaCl}_{2}$ on day 7 (A) showing hyperechoic areas within the parenchyma (arrows). By day 14, the hyperechoic areas on the testes (arrows) were increased (B). The hyperechoic areas (arrows) were present at day 21 (C).

The semen volume of the olive oil castrated bucks was not significantly decreased as the $\mathrm{CaCl}_{2}$ group but the appearance changed to yellow-straw color. This suggests that no significant damage occurred to testes function in olive oil castrated bucks compared with the other castration methods studied. The yellowish tinge of the ejaculate could be attributed to the olive oil injection getting into the ejaculate through the direct injection of the olive oil into the testis parenchyma.
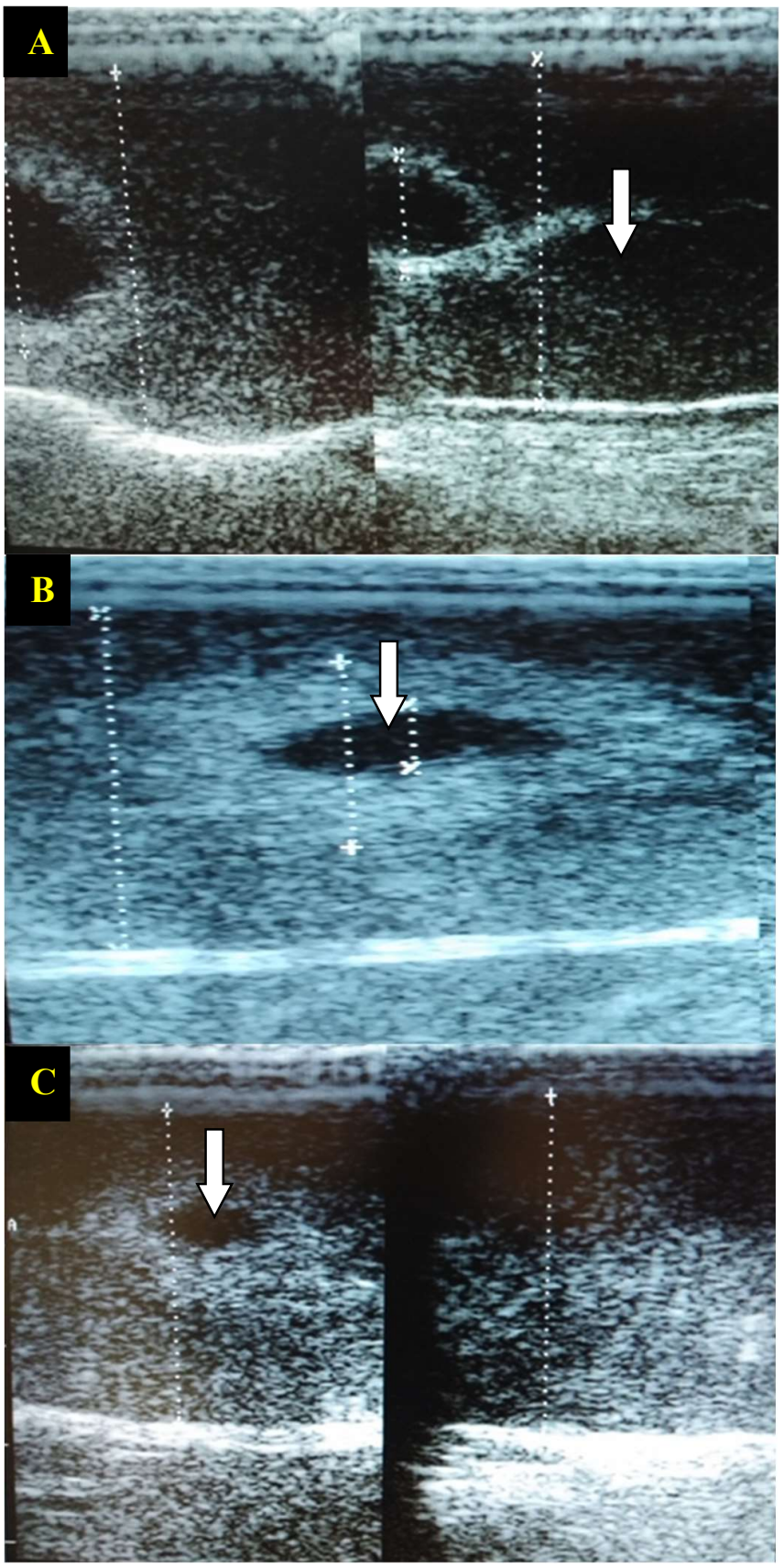

Figure 4: Sonogram of testes chemically castrated with olive oil on day 7 (A) showing a central hypoechoic area (arrows) surrounded by clearly distinguishable hyperechoic areas within the parenchyma (Arrows). By day 14 (B), and day 21 (C) (arrows), the hyperechoic areas were still present but noticeably smaller surrounded by less hyperechoic areas (arrows).

The mass motility, concentration and viability of bucks in the Burdizzo castrated bucks did not decrease significantly. This finding suggests that failure of castration had occurred. This failure has been reported previously in lambs and calves (Stafford et al., 2000). 
The progressive forward spermatozoa motility was markedly decreased on day 7 in the Burdizzo, $\mathrm{CaCl}_{2}$ and Olive oil castrated groups compared with the control group. Among the groups, the spermatozoa were non motile earlier in the $\mathrm{CaCl}_{2}$ castrated group at day 14 . However, at 60 days after castration, the Burdizzo and olive oil castrated groups had non motile spermatozoa.

The concentration of spermatozoa also decreased significantly on day 7 in all the Burdizzo, $\mathrm{CaCl}_{2}$ and Olive oil castrated goats. Thereafter, the least motility was observed in the $\mathrm{CaCl}_{2}$ castrated group.

The proportion of live spermatozoa also decreased significantly on day 7 in all the Burdizzo, $\mathrm{CaCl}_{2}$ and Olive oil castrated goats. Thereafter, the least motility was observed in the $\mathrm{CaCl}_{2}$ castrated group. Interestingly, by day 60 , all the spermatozoa seen in the semen of $\mathrm{CaCl}_{2}$ and olive oil castrated goats were dead. A few live spermatozoa were seen in the smear of some Burdizzo castrated bucks.

The changes observed in semen quality such as decreased ejaculate volume, azoospermia, poor spermatozoa motility, high proportion of dead cells, varying semen colour, are indications of successful castration (Jana et al., 2005; Sawhney 2016). In the current study, azoospermia was observed from day 14 post castration as well as other semen indices signifying non fertility. The indices were observed earlier in the $\mathrm{CaCl}_{2}$ castrated bucks suggesting that it was the most effective chemical castration method. This agrees with previous reports where $\mathrm{CaCl}_{2}$ was evaluated in bucks (Jana et al., 2005; Al-Asadi and Al-Kadi 2012), dogs (Jana and Samanta 2007; Leoci et al., 2014; Leoci et al. 2019), guinea pigs (Sen et al., 2017). A detailed review of the use of $\mathrm{CaCl}_{2}$ based solutions, their effectiveness and some factors that could improve castration responses had been published (Cavalieri 2017).

The sonogram of the normal uncastrated testes showed low to moderate but homogenous echogenicity of the parenchyma with hyperechogenic vaginal tunic. This echotexture mirrors the findings in (Sakthivel et al., 2013; Olatunji-Akioye et al., 2018) and rams (Gouletsou et al., 2003; Andrade et al., 2014). In the Burdizzo castrated bucks, sonogram of testes showed low to moderate parenchyma. The echogenicity increased on days 14 and 21 .

Sonogram of testes castrated with $\mathrm{CaCl}_{2}$ showed discreet focal hyperechoic areas within the parenchyma. The hyperechoic areas were surrounded by anechoic areas. A recent study by Leoci et al. (2019), stated that these anechoic areas corresponded to areas of tissue damage caused by the $\mathrm{CaCl}_{2}$ injected. These hyperechoic areas increased and persisted in their echogenicity, probably due to the sclerosed parenchyma tissues.

These hypoechoic areas persisted until day 28 and are likely the non-absorbed olive oil deposited within the parenchyma tissue.
A single bilateral intratesticular injection of $\mathrm{CaCl}_{2}$ resulted in aspermia and azoospermia within 14 days of injection. Burdizzo castration was effective but was associated with failure to completely crush the spermatic cord in some bucks. Semen volume was not affected by castration with olive oil but the spermatozoa concentration and viability were completely absent by day 60 after castration.

In conclusion, intratesticular injection with $\mathrm{CaCl}_{2}$ injection in Sahel bucks resulted in aspermia and azoospermia. Thus, $\mathrm{CaCl}_{2}$ solution provided the best castration outcomes compared with Burdizzo and olive oil. It is recommended that methods be developed to mitigate the complications such as swelling and pain.

\section{Acknowledgements}

This study was funded from a grant by the Tertiary Education Trust Fund through the Centre for research and Innovation, University of Maiduguri. The authors' also wish to acknowledge the assistance provided by the laboratory staff of Departments of Veterinary Surgery and Radiology, and Theriogenology, Faculty of Veterinary Medicine, University of Maiduguri, Nigeria.

\section{Conflict of Interest}

The authors do not have any conflict of interest to declare.

\section{Authors Contribution}

$\mathrm{AM}$ and BMM designed and supervised the work. DL performed the experiments, analysed the data and wrote the draft manuscript. All authors have read and approved the final manuscript.

\section{REFERENCES}

Al-Asadi R and Al-Kadi KK (2012). Non-surgical castration in bucks a comparative study between chemical castration and external ligation of the spermatic cord. AL-Qadisiyah Journal of Veterinary Medicine Sciences, 11 (1):92-102

Andrade A, Soares A, Freitas F, Silva S, Peña-Alfaro C, Batista A and Guerra M (2014). Testicular and epididymal ultrasonography in Santa Inês lambs raised in Brazil. Animal Reproduction, 11:110-118

Bakir B, Gulyuz F, Karaca F, Yuksel H, Sahin A and Uslu BA (2002). Chemical castration in dogs. Journal of Health Science, 8 (1-3):6-8

Cavalieri J (2017). Chemical sterilisation of animals: A review of the use of zinc-and $\mathrm{CaCl}_{2}$ based solutions in male and female animals and factors likely to improve responses to treatment. Animal Reproduction Science, 181:1-8

Currah JM, Hendrick SH and Stooley JM (2009). The behavioral assesment and alleviation of pain associated with castration in beef calves treated with flunixin meglumine and cauda lidocaine epidural anesthesia with epinephrine. Canadian Veterinary Journal, 50:375-382 
Da RP, Mustafa AS and Talwar GP (1982). Atrophy of seminiferous tubules in mouse testes after intratesticular injection of BCG and their regeneration Archive of Andrology, 9 (3):244-250

De Faveri D, Aliakbarian B, Avogardo M, Perego P and Converti A (2008). Improvement of olive oil phenolic content by means of enzyme formulation: Effects of different enzyme activities and levels. Biomedical Engineering Journal, 41:149-156

Fordyce D, Hodge PB, Beaman NJ, Laing AR, Campero C and Shepherd RK (1989). An evaluation of calf castration by intratesticular injection of lactic acid solution Australian Veterinary journal, 66:272-276

Gouletsou PG, Amiridis GS, Cripps PJ, Lainas T, Deligianis K, Saratsis P and Fthenakis GC (2003). Ultrasonographic appearance of clinically healthy testicles and epididymis of rams. Theriogenology, 59:1959-1972

Hasan M, Miah M, Rosy T, Jha P and Juyena N (2016). Serum testosterone concentration in surgically castrated Black Bengal goats. Bangladesh Veterinarian, 33 (2):71-77

Ibrahim A, Ali MM, Abou-Khalil NS and Ali MF (2016). Evaluation of chemical castration versus surgical castration in donkeys: testosterone as an endpoint marker. BMC Veterinary Research, 12:46

Ijaz A, Abalkhail AA and Khamas WAH (2000). Effect of intratesticular injection of formalin on seminiferous tubules in Awasi lambs. Pakistan Veterinary Journal,20 (3):129-134

Jana K and Samanta PK (2007). Sterilization of male dogs with a single intratesticular injection of calcium chloride a dose dependent study Contraception, 75:390-400

Jana K, Samanta PK and Gosh D (2005). Evaluation of single intratesticular injection of calcium chloride for nonsurgical sterilization of male Black Bengal goats Capra hircus: a dose-dependent study. Animal Reproduction Science, 86 89-108

Leoci R, Aiudi G, Cicirelli V, Brent L, Iaria C and Lacalandra GM (2019). Effects of intratesticular vs intraepididymal calcium chloride sterilant on testicular morphology and fertility in dogs. Theriogenology, 4756-61

Leoci R, Aiudi G, Slvestre F, Lissner E and Lacalandra G (2014). A dose-finding, long-term study on the use of calcium chloride in saline solution as of non-surgical sterilization in dogs Acta Veterinaria Scandanavia, 56:63

Mohammed A and James F (2013). Chemical castration by a single bilateral intra-testicular injection of chlorhexidine gluconate and cetrimide in bucks. Sokoto Journal of Veterinary Sciences 11 (1):62-65
Molony V, Kent JE and Robertson IS (1995). Assessment of acute and chronic pain after different methods of castration of calves. Application of Animal Behavioural Science, 46:33-48

Neto OA, Gasperin BG, Rovani MT, Ilha GF, Nóbrega Jr JE, Mondadori RG, Gonçalves PB and Antoniazzi AQ (2014). Intratesticular hypertonic sodium chloride solution treatment as a method of chemical castration in cattle. Theriogenology, 82 (7):1007-1011

Olatunji-Akioye A, Afonja V and Saka B (2018). Ultrasonographic Features of Testes of West African Dwarf Bucks. Iranian Journal of Veterinary Surgery, 13 (2):34-39

Paiva MF, Rodrigues V, Calheirs R and Marques MPJ (2011). Characterization of antioxidant olive oil biophenols by spectroscopic methods. Science Food and Agriculture. (2):309-314.

Rajkumar D (2013). Minimization of pain in cattle castration with respect to method, age and pain relief. In, vol. http://vip.vetsci.usyd.edu.au/content upload/content3164/RajkumarDharshinea.pdf/retrieved,

Sakthivel J, De A, Kundu A, Roy K, Sunder J, Kundu M, Balakrishnan M, Chand S and Ahmed Z (2013). Sonographic characteristics of goat testis on water bath based ultrasonography, vol 152. pp 79-87

Sawhney P (2016). Burdizzo versus pinhole castration in bucks and cattle calves. In, vol. Nanaji Deshmukh Veterinary Science University Jabalpur,

Sen C, Yumusak N, Faundez R, Temamogullari F and Taskin A (2017). Evaluation of intra-testicular injections of calcium chloride and 4-vinylcyclohexene 1, 2 monoepoxide for chemical sterilization in guinea pigs. Polish Journal of Veterinary Sciences, 20 (2):251-260

Stafford KJ, Mellor DJ and McMeekan CM (2000). A survey of the methods used by farmers to castrate calves in New Zealand. New Zealand Veterinary Journal, 48:16-18

Stoffel MH, VonRotz A, Kocher M, Merkli M, Boesch D. and Steiner A (2009). Histological assessment of testicular residues in lambs and calves after Burdizzo Castration. Veterinary Research, 164:523-527

Visioli F, Poli A and Galli C (2002). Antioxidant and other biological activities of phenols from olives and olive oil. Journal of Medicinal Research Review, 22:65-75

Webe JP and Barr KJ (1984.). The control of male fertility by 1,2,3-trihydroxypropan [THP;glycerol]; rapid arrest of spermatogenesis without altering libido, accessory organs, gonadal steroidogenesis and serum testosterone, LH and FSH. Journal of Contraception, 29.:291-30 
